\title{
Convergence of approximate solutions for singular difference systems with maxima
}

\author{
Xiang Liu ${ }^{1}$, Christopher GOODRICH ${ }^{2}$, and Peiguang Wang ${ }^{3}$ \\ ${ }^{1}$ Hebei Normal University \\ ${ }^{2} \mathrm{UNSW}$ \\ ${ }^{3}$ Hebei University
}

September 24, 2021

\begin{abstract}
In this paper, by introducing a new singular fractional difference comparison theorem, the existence of maximal and minimal quasi-solutions are proved for the singular fractional difference system with maxima combined with the method of upper and lower solutions and the monotone iterative technique. Finally, we give an example to show the validity of the established results.
\end{abstract}

\section{Hosted file}

Monotone iterative_August_6.pdf available at https://authorea.com/users/342072/articles/ 538461-convergence-of-approximate-solutions-for-singular-difference-systems-with-maxima 